\title{
Emoções e redes colaborativas na resiliência informacional
}

\author{
Emoções e redes colaborativas na resiliência informacional
}

Fellipe Sá Brasileiro ${ }^{\mathrm{a}, *}$

RESUMO: Discute o conceito de resiliência informacional a fim de desenvolver uma relação entre emoções e redes colaborativas em contextos de ruptura do cenário de informação. Decorre de uma análise conceitual baseada em pesquisas empíricas que exploram o conceito de resiliência informacional no campo da informação. Observa que as emoções determinam as redes colaborativas e a transição frente às incertezas informacionais. Conclui que a perspectiva das emoções pode auxiliar a análise dos processos coletivos de enfrentamento, transição e autonomia informacional em contextos de ruptura dos cenários de informação, como o da infodemia sanitária digital gerada pela COVID-19.

Palavras-chave: Resiliência Informacional; Práticas Informacionais; Redes Digitais; Emoções.

ABSTRACT: Discusses the concept of informational resilience in order to develop a relationship between emotions and collaborative networks in contexts of disruption of the information landscape. It stems from a conceptual analysis based on empirical research that explores the concept of informational resilience in the field of information. Notes that emotions determine collaborative networks and the transition in the face of informational uncertainties. It concludes that the perspective of emotions can help the analysis of collective processes of coping, transition and informational autonomy in contexts of rupture of information scenarios, such as the digital health infodemia generated by COVID-19.

Keywords: Information Resilience; Information Practice; Digital Networks; Emotions.

\footnotetext{
a Departamento de Comunicação, Programa de Pós-Graduação em Comunicação, Universidade Federal da Paraíba, João Pessoa, PB, Brasil.

*Correspondência para/Correspondence to: Fellipe Sá Brasileiro. E-mail: fellipesa@hotmail.com.

Recebido em/Received: 18/08/2020; Aprovado em/Approved: 04/11/2020.

Artigo publicado em acesso aberto sob licença CC BY 4.0 Internacional $@$
} 


\section{INTRODUÇÃO}

O conceito de resiliência informacional criado por Lloyd (2014) é fundamental para o estudo da transição no campo da informação, sobretudo se o enfoque se concentra na correlação entre as práticas de letramento informacional durante a transição, agenciadas por sujeitos que lidam com desafios, e as transformações decorrentes. Nesse panorama, resumidamente, a resiliência informacional abrangeria a capacidade de se orientar dentro de uma ambiência informacional desconhecida, de se adaptar ao seu modus operandi e, conjuntamente, de ressignificar/reconstruir o cenário informacional' frente ao novo ambiente informacional.

O processo de transição de uma ambiência informacional para outra - envolvendo a construção e transformação de práticas - consiste num fenômeno complexo. Isso porque a transição não acontece de maneira linear e previsível. Decorre de rupturas das bases informacionais e depende do enfrentamento das barreiras estruturais e pessoais emergentes, as quais tendem a dificultar a (re) construção das bases rompidas (LLOYD, 2015). Somadas a essas barreiras, outras complexidades problematizam as experiências transitórias, como a virtualização da vida contemporânea (SODRÉ, 2013), a reboque das práticas sociotécnicas (MORGANTHOMAS et al, 2020), que, além de fragmentarem a informação, ampliam a diáspora digital ${ }^{2}$.

Por esses e outros fatores (e. g. hipercirculação da informação e desinformação), a transição está condicionada à articulação de um emaranhado de elementos interligados em etapas interdependentes, caracterizando-se, assim, como contextual, multidimensional e processual. Nessa complexidade, o conceito de resiliência informacional emerge como alternativa para os estudos sobre sujeitos que lidam com desafios à medida que permite objetificar a transição em sua totalidade, isto é, abarcando transversalmente a articulação entre seus elementos, etapas e efeitos. Para tanto, suscita a integração de outros conceitos (e. g. práticas informacionais, mediação, letramento, redes sociais), operando como atrator e, logo, estruturando um sistema entre eles.

No campo da informação, o conceito de resiliência informacional é desenvolvido a partir dos estudos de Lloyd (2014; 2015) sobre práticas de letramento informacional em saúde no contexto de transição de refugiados. A autora mostra que as práticas situadas em espaços cotidianos - envolvendo tanto a interação colaborativa entre refugiados quanto as conexões casuais e relacionais com agentes mediadores situacionais - determinam a construção de um novo cenário informacional, visto que mobilizam os capitais sociais e culturais carentes. Nesse caminho, partindo de um estudo empírico sobre a transição de mulheres primíparas, buscamos incorporar ao conceito os fatores emocionais que determinam a colaboração em redes digitais (BRASILEIRO, 2019). Ademais, sublinhamos a importância dos capitais emocionais na construção dos novos cenários, de modo a sedimentar uma relação entre emoções e letramento informacional.

Em ambos os estudos, a concepção de resiliência é desenvolvida numa abordagem de matriz sociocultural. Enxergamos proximidades entre essa abordagem e a concepção

\footnotetext{
${ }^{1}$ Entendidos por Lloyd $(2014 ; 2015)$ como os espaços que fazem referência às modalidades e fontes de informação habituais dos sujeitos.

2 Entendida por González de Gómez (2004) como as experiências instáveis dos sujeitos, relacionadas aos efeitos da convergência tecnológica propiciada pela internet, que abarca desde o deslocamento de seus lugares de enunciação de ponto de partida até os desafios à autonomia informacional em contextos heterológicos digitais.
} 
latino-americana da resiliência (OJEDA, 2005), que permite "repensar o objeto: dos atributos dos indivíduos às condições coletivas de grupos humanos ou sociedades para enfrentar adversidades e procurar, em conjunto, a obtenção de seu bem-estar" (OJEDA, 2005, p. 49). Nesse sentido, observamos que, no campo da informação, os estudos sobre a resiliência têm como concepção o coletivismo presente no conceito de práticas informacionais, em detrimento do enfoque no individuo, característico do conceito de comportamento informacional (SAVOLAINEN, 2007). Tal coletivismo situa as práticas informacionais como "formas social e culturalmente estabelecidas para identificar, buscar, usar e compartilhar informações" (SAVOLAINEN, 2008, p. 2).

Contudo, destacamos que o coletivismo das práticas informacionais pode assumir perspectivas distintas vinculadas à Teoria Social. Considerando o caráter contextual e emergente da resiliência informacional, que envolve ruptura e reconstrução das formas socioculturais, o enfoque coletivista sobre as práticas que sublinhamos neste estudo é o da ontologia contextual (SCHATZKI, 2005), que, ao entender a vida social no nível das práticas, evidencia o caráter determinante das ações coletivas situadas e seus arranjos materiais - nas formações. Dito isso, partimos da definição de Lloyd (2011, p. 285, tradução nossa) sobre as práticas informacionais: "uma série de atividades e habilidades relacionadas à informação, constituídas, justificadas e organizadas por meio dos arranjos de um site social, e mediadas social e materialmente com o objetivo de produzir entendimento compartilhado e acordo mútuo sobre formas de conhecer".

Nesse sentido, este artigo objetiva discutir o conceito de resiliência informacional a fim de desenvolver uma relação entre emoções e redes colaborativas em contextos de ruptura do cenário de informação. Tomando como base os estudos de Lloyd (2014; 2015) sobre práticas de letramento informacional de refugiados, buscando relacionálos a uma perspectiva socioemocional da transição (BRASILEIRO, 2019), de abordagem interacionista (ARAÚJO, 2012), esperamos delinear algumas questões associadas às emoções a fim de aproximar o conceito das dinâmicas informacionais que envolvem os sentimentos coletivos na ambiência digital. Acreditamos que essas dinâmicas informacionais e emocionais podem determinar a (re) construção de cenários informacionais rompidos, a exemplo do cenário (des) informacional eclodido pela COVID-19.

\section{RESILIÊNCIA INFORMACIONAL: ESTRUTURA CONCEITUAL}

O conceito de resiliência informacional é emergente no campo da informação. Foi elaborado pela pesquisadora Annemaree Lloyd, que se dedica ao estudo das temáticas "Information Practices" e "Information Literacy". A partir dessas temáticas, uma questão investigativa desenvolvida pela autora, ao nosso ver, incita a emergência do conceito: Como pessoas que experimentam contextos de vida adversos, suscetíveis ao estresse e às incertezas, transitam de seus ambientes informacionais habituais para outros ambientes desconhecidos, a ponto de desenvolverem as competências informacionais necessárias para seguirem em frente?

Tal questão, embora relacionada às questões da Information Literacy, demarca um fenômeno original - a transição. Este, por sua vez, pode ser percebido como uma experiência diaspórica - decorrente da ruptura das bases informacionais - orientada à construção de novas práticas de letramento. De acordo com Lloyd (2010, p. 245, tradução nossa), o letramento informacional consiste em "prática de informação central e crítica, que constrói a capacidade das pessoas de negociar ambientes sociais e tecnológicos cada vez mais complexos e que facilita uma forma de conhecer as 
modalidades de informação dentro de um ambiente". No contexto da transição, as práticas de letramento informacional assumem uma dinâmica situacional à medida que se vinculam ao caminho desconhecido. Ou seja, precisam ser (re) construídas situacionalmente a partir de novas experiências informacionais (interações das pessoas com fontes de informações diversas) a fim de facilitar a conexão com o novo ambiente informacional (LLOYD, 2014; 2015). Nessa perspectiva, Lloyd demarca o letramento como prática sociocultural derivada do contexto, por seu formato e suas prefigurações, e das interações sociais situadas, por sua emergência.

Assim, o fenômeno da transição (informacional), quando delimitado como objeto de estudo, pode ser compreendido pela heurística do conceito de resiliência informacional. Lloyd (2014) demonstra que a resiliência informacional emerge como a capacidade de orientação, ajustamento e ressignificação frente às adversidades e incertezas, a ponto de desenvolver as competências informacionais necessárias à transição. Para a autora, orientação (desenvolver meios de conhecer a informação), adaptação (aprender modos de saber e fazer) e ressignificação (reformular modos de saber e fazer) são experiências que se dão através de estratégias coletivas em espaços cotidianos. A esse respeito, Lloyd (2014) desenvolve um estudo empírico com refugiados que experimentam um novo ambiente sanitário para explorar como se desenvolve as práticas de letramento - durante a transição - e a resiliência informacional (BRASILEIRO, 2017).

Considerando esse estudo, alguns aspectos das redes sociais merecem ser destacados para a compreensão da estrutura do conceito de resiliência informacional. Para os fins didáticos deste artigo, esses aspectos foram organizados em duas perspectivas complementares: uma relacional e outra socioemocional. Juntas, ao nosso ver, podem contribuir para o estudo da transição na dimensão interacional das redes digitais frente aos desafios "infodêmicos" contemporâneos.

\section{Perspectiva relacional}

Partindo de uma abordagem sociocultural, ancorada na Teoria da Prática de Theodore Schatzki, o conceito de resiliência informacional emerge da observação empírica do fenômeno da transição informacional. Considerando o caráter coletivista e social evidenciado, o esforço de estruturação do conceito envolve a articulação entre as categorias empíricas cunhadas e um conjunto de teorias sociais. Nessa direção, originalmente, Lloyd (2014; 2015) contribui para o desenvolvimento do que interpretamos como sendo uma "perspectiva relacional" do conceito.

Essa perspectiva pode ser evidenciada a partir do destaque da autora sobre a importância dos laços sociais, estabelecidos situacionalmente em espaços cotidianos, para a resiliência informacional. Para Lloyd (2014), a Teoria da Força dos Laços Fracos, proposta por Granovetter, é central ao funcionamento das bases informacionais e espaços cotidianos, uma vez que sugere

[...] que com conexões próximas (laços fortes), há um potencial para os membros desenvolverem a mesma base informacional. Laços fracos podem ser mais benéficos ao buscar informações de saúde porque transcendem a base de laços fortes e podem oferecer perspectivas ou informações únicas (Granovetter 1973; Johnson e Case 2013). No caso de reassentamento de refugiados, espaços cotidianos e bases informacionais contribuem para a estratégia de enfrentamento coletivo, oferecendo perspectivas e avisos que refletem as narrativas dominantes sobre saúde às quais os 
refugiados devem se conectar a fim de alcançar resultados de saúde eficazes e bem-sucedidos (LLOYD, 2014, p. 63, tradução nossa).

Além disso, Lloyd (2014) destaca que, quando as bases de informação e conhecimento são desestruturadas, os sujeitos necessitam reconstruir os seus capitais sociais e culturais. Nesse ponto, Lloyd (2015) se baseia na conceito de capital social de Bourdieu (1986) - "conjunto dos recursos reais ou potenciais que estão ligados à posse de uma rede durável de relações mais ou menos institucionalizadas de interconhecimento e de inter-reconhecimento mútuos" (p. 248) - para relacionar, dentro de uma perspectiva informacional, os recursos com as "informações e conhecimentos sobre a natureza, fluxo e localização de informações e a operacionalização de habilidades informacionais num sistema social" (LLOYD, 2015, p. 1038, tradução nossa).

Nessa direção, a autora sublinha a importância do acesso aos relacionamentos - e aos capitais incorporados - para a ampliação dos capitais culturais (BRASILEIRO, 2017). Assim, adotando como exemplo o contexto de refugiados, ela destaca que, ao chegarem a novos países sem conexões ou apoio de grupos e redes sociais, os refugiados devem aprender a criar suas relações sociais com grupos estabelecidos e situados, que servirão como ponte para o acesso aos capitais carentes e, logo, para a construção de novos cenários (LLOYD, 2015). A esse respeito, Lloyd (2015) também considera que os conceitos de "capital de ligação e de pontes", de Putnam (2000), apresentam contribuições ao entendimento do processo de resiliência informacional.

Em suma, Lloyd (2014; 2015) deixa claro que o capital social à informação pode ser adquirido e apropriado pelos sujeitos por meio da combinação das diferentes formas de redes sociais: (i) conexões com os laços fortes (relacionadas aos capitais de ligação) agem nas trocas de reciprocidade e confiança; (ii) conexões com os laços fracos (relacionadas aos capitais de ponte) agem no acesso aos novos recursos informacionais. Vale ressaltar, contudo, que os contextos de transição experimentados apresentam peculiaridades quanto às condições, recursos ou restrições às conexões com fontes, pessoas, grupos e instituições. Isso significa dizer que, seguindo uma abordagem empírica de ontologia contextual (SCHATZKI, 2005), cada contexto deve ser analisado frente às dinâmicas situacionais que envolvem as interações informacionais em detrimento de compreensões pré-estabelecidas sobre as realidades. Ou seja, considerando o letramento informacional como prática sociocultural emergente, e não apenas como influência estrutural de um corpo de conhecimento unificado ou crenças imutáveis (HICKS; LLOYD, 2016).

Tomando o contexto de transição dos refugiados como exemplo, caracterizado pela desconexão com as bases de conhecimento e pelas barreiras de letramento, as conexões se desenvolvem predominantemente de forma situacional com outras pessoas desconhecidas que agem como intermediários de informação em espaços cotidianos diversos e, logo, como pontes para a formação das redes sociais (LLOYD, 2014; 2015). No contexto de mulheres primíparas, por sua vez, a transição é significativa, envolvendo "ruptura, reconstrução de si mesma com uma nova posição [...] que se auto-organiza no self da mulher, reconfiguração de práticas sociais, reconstrução dos significados de maternidade construídos ao longo da trajetória de vida e ancorados nos padrões normativos da cultura" (SILVA, 2012, p. 45). Tal contexto evidencia um dilema: os laços fortes, embora percebidos como redes de confiança, podem ser julgados como limitados às informações relevantes, ao passo que os laços fracos, embora percebidos como relevantes, podem denotar desconfiança às trocas de informações pessoais. Diante desse dilema, precisam construir confiança nos laços fracos para reconstruir suas práticas (BRASILEIRO, 2019). 
Fica evidente, portanto, que as situações/conexões decorrentes das experiências informacionais, durante a transição, são fundamentais às relações e redes necessárias à resiliência informacional. Contudo, as situações/conexões podem apresentar dificuldades relacionadas à desinformação, isto é, informações ambíguas, incertas, imprecisas (KARLOVA; FISCHER, 2013). Para Hicks e Lloyd (2016), uma delas é saber o que é verdade quando se juntam fragmentos de informações, podendo ocorrer "quando as estratégias de juntar informações são fragmentais, e pequenos segmentos de informação de várias fontes são postos juntos aleatoriamente sem uma estratégia de letramento informacional coesiva sendo praticada" (p. 339-340, tradução nossa).

De modo oportuno, tal experiência pode ser observada durante a emergência de saúde pública da COVID-19, particularmente frente ao que se denominou de infodemia: "um excesso de informações, algumas precisas e outras não, que tornam difícil encontrar fontes idôneas e orientações confiáveis quando se precisa" (OPAS, 2020, p. 2). Tratase de um fenômeno amplificado pelo compartilhamento de informações nas redes sociais (ZAROCOSTAS, 2020), envolvendo rumores e manipulação com intenções duvidosas, com implicações à encontrabilidade de informações, à tomada de decisões, à depressão e exaustão emocional, entre outras (OPAS, 2020). Embora os esforços das autoridades de saúde nas mídias sociais demonstrem eficiência no combate a essa desinformação (O’BRIEN et al, 2020), percebe-se que, no início da crise, o combate eficaz aos efeitos infodêmicos ficou a cargo das ações informacionais dos usuários.

Significa dizer que, durante a crise, a encontrabilidade de informações confiáveis, a tomada de decisões informadas e a motivação para agir, por exemplo, dependem de um conjunto de atividades e habilidades relacionadas às informações sobre COVID-19, estabelecidas em meio aos entendimentos partilhados construídos a partir das conexões com pessoas/fontes mediadas pelas plataformas digitais. Ou seja, decorrem das práticas de letramento informacional construídas coletivamente na situação (LLOYD, 2014; 2015). De notar que, devido ao distanciamento social, a COVID-19 revelou um protagonismo das plataformas digitais neste processo interacional.

Contudo, ressaltamos a complexidade dessas plataformas digitais em virtude da hiperconexão e superexposição nas redes sociais (RECUERO, 2013), tanto nos aspectos infodêmicos (acesso às informações confusas, descontextualizadas e contraditórias que circulam nas redes), quanto nos aspectos da socialidade (tensionamento das identidades virtuais nas interações). Com efeito, ambos problematizam a conciliação entre os objetivos informacionais e conflitantes (BRASHERS et al, 2002), necessária ao gerenciamento de incertezas.

Pensando nisso, e em possíveis dificuldades de caráter interacional nas redes digitais, argumentamos que a coesão social se configura como elemento central para o bom desenvolvimento das estratégias informacionais coletivas digitais de letramento e, assim, para a resiliência informacional. Isso porque percebemos que as dificuldades potenciais de uma estratégia coletiva - desinformação, desconfiança nas fontes, conflito de valores, descompromisso ético, coordenação dos objetivos informacionais e/ou conflitantes - são transcendidas à medida que os sujeitos passam a ter a consciência coletiva informacional direcionada ao bem comum. Entretanto, não se trata da coesão social proveniente das estruturas sociais prévias, a exemplo de organizações tradicionais, mas, peculiarmente, da coesão negociada e construída nas situações entre dois ou mais atores que não necessariamente pertencem a um mesmo estrato social (BRASILEIRO, 2019).

Partindo desse princípio, resta-nos incorporar ao sistema conceitual da resiliência informacional os fatores emocionais que determinam a interação colaborativa e a construção das relações sociais favoráveis ao desenvolvimento de perspectivas únicas 
de informação. Nesse sentido, lançamos mão de um olhar socioemocional sobre o fenômeno da transição que, assentado num viés de complemento e não de oposição, resulta no que denominamos, por enquanto, de perspectiva socioemocional da resiliência informacional. Tal perspectiva, além de considerar o processo de transição pelo plano das conexões situacionais, pode contribuir para a perspectiva relacional à medida que incorpora as microdinâmicas emocionais fundamentais à coesão social.

\section{Perspectiva socioemocional}

A análise do processo coletivo e dinâmico de transição informacional sob o prisma das emoções pode ser denominada, provisoriamente, de "perspectiva socioemocional" do processo de resiliência informacional. Nessa perspectiva, os elementos que para Lloyd (2014) constituem os processos de construção de cenário, de encontrabilidade de informações e de agrupamento de informações fundamentais às experiências de orientação, ajustamento e ressignificação (LLOYD, 2014) - podem ser observados, empiricamente, como sendo processos emocionais.

Por processos emocionais, entendemos as microdinâmicas emocionais nas situações de interação capazes de determinar as relações sociais e as percepções/sentimentos sobre a realidade social. Implica dizer que a intersubjetividade e a coesão social, quando traduzidas em observáveis, são, na realidade, construções emocionais carregadas de sentimentos, que, por sua vez, resultam das microdinâmicas emocionais individuais e coletivas próprias das interações (COLLINS, 2004).

Tal entendimento se desenvolve numa abordagem interacionista especialmente a denominada por Collins (2004) de microssociologia radical - atrelada à Sociologia das Emoções. Essa abordagem se propõe a aproximar as práticas sociais e as estruturas simbólicas, sem se ater às estruturas tradicionais de poder, dando centralidade aos processos emocionais. Dessa maneira, evoca autonomia para as ações situadas e para a emergência e reprodução da coesão social.

O eixo teórico central da referida abordagem é o modelo teórico sobre os rituais de interação do sociólogo estadunidense Randall Collins. O modelo teórico de Collins (2004), baseado na sociologia de Émile Durkheim e Erving Goffman, põe em evidência alguns elementos de natureza não racional e coletiva como centrais à coesão social numa dimensão situacional e microssocial, a saber: os rituais de interação, as emoções, a solidariedade, a emoção compartilhada, a energia emocional, os símbolos de pertencimento e os sentimentos morais (COLLINS, 2004).

Partindo do princípio de que os encontros entre duas ou mais pessoas nos espaços cotidianos envolvem objetivos conflitantes e/ou ambivalências emocionais (BRASHERS et al, 2002; GOFFMAN, 1967), provenientes das regras morais que ordenam as interações e das marcas emocionais/simbólicas de estratificação que as pessoas trazem consigo nos encontros, o modelo de Collins (2004) permite observar a coesão entre pessoas que não necessariamente pertencem a uma mesma estratificação social (classe econômica, status, poder), assim como a ampliação dessa estratificação, a partir das emoções agenciadas nos encontros interacionais.

A microdinâmica emocional, que incide sobre a coesão social e as ações futuras em outras situações, abrange, para Collins (2004): (i) emoções transitórias que particularizam uma determinada situação e atraem as pessoas; (ii) transformação dessas emoções transitórias em Energia Emocional (EE) em nível coletivo (correspondente à "experiência intensa de emoção compartilhada" ou à 
"efervescência coletiva", nos termos de Durkheim); (iii) os resultados da Energia Emocional (EE) em nível individual, que determinarão as ações individuais futuras.

As emoções transitórias são as emoções manifestadas inicialmente durante um determinado encontro (medo, alegria, raiva, tristeza, frustração). À medida que as pessoas focam suas atenções em uma atividade comum, tomando consciência da consciência de cada um (foco de atenção mútua) e do que o outro está sentindo (humor compartilhado), essas emoções transitórias se transformam numa experiência de emoção compartilhada (COLLINS, 2004). Quanto maior a sincronia e intensificação de feedbacks na interação, segundo Collins (2004), maior a intensidade dessa experiência compartilhada, a qual é capaz de dominar as consciências dos envolvidos. Como resultado, tem-se: a construção coletiva de sentimentos duradouros de solidariedade e moralidade, que podem ser cristalizados em símbolos de pertencimento (palavras, gestos, pessoas, objetos, etc.); e, conjuntamente, a construção individual de Energia Emocional (EE), constituída por sentimentos de confiança, força, entusiasmo e iniciativa (COLLINS, 2004).

Toda essa microdinâmica, quando posta em perspectiva com a informação e com as práticas informacionais, contribui para o entendimento socioemocional do processo de transição informacional. Importa dizer que partimos do pressuposto de que a prática informacional, na perspectiva de um fenômeno social e cultural que vincula a subjetividade e a coletividade (MCKENZIE 2003; SAVOLAINEN, 2008; COX, 2012; ARAÚJO, 2017; ROCHA; GANDRA, 2018), consiste, também, num processo emocional, que vincula emoções individuais e coletivas.

Nessa perspectiva, a "dimensão individual" da prática informacional remeteria à "dimensão emocional" dos sujeitos: (i) nos processos perceptivos/imaginativos/de significação; (ii) nos processos comunicativos e/ou de apresentação de si. Nos primeiros, o estado emocional - que pode ser referente tanto às emoções cristalizadas na consciência e no corpo quanto às emoções situacionais - determina a seleção das fontes e o julgamento de valor das informações, ao mesmo passo que é constantemente (re) configurado e estimulado pelo ambiente informacional. Nos segundos, o estado emocional determina os modos comunicacionais frente ao(s) outro(s), envolvendo os modos de conexão e interação com as pessoas/fontes, o compartilhamento de informações, a expressão corporal e virtual do "eu", o gerenciamento da identidade, e outras.

Os modos comunicacionais, por sua vez, revelam a dimensão coletiva da relação entre informação e emoção. Ao destacarmos a presença do(s) outro(s), sublinhamos o fato de que os sujeitos não agem com a informação de maneira atomizada no tempo e no espaço, mas, sobretudo, agem em relação a um coletivo informacional - a um valor de informação compartilhado (COX, 2012) - constituído a partir das configurações de seus contextos e situações. Esse coletivo, embora seja firmado pelo universo simbólico/cognitivo/imaginário dos sujeitos, emerge de experiências intensas de emoções compartilhadas atreladas a um valor informacional, que formam a consciência sobre os outros e tensionam a consciência sobre si. Afinal, como argumenta Collins (2004), os valores, quando existem, são cognições infundidas pelas emoções. Numa perspectiva empírica e observável, assim, podemos dizer que as emoções socialmente experimentadas e compartilhadas - cristalizadas em símbolos de associação, carregadas de sentimentos individuais e coletivos - determinam a constituição de práticas informacionais e podem moldar o cenário informacional.

Essa perspectiva socioemocional pode ser observada empiricamente a partir de uma pesquisa acerca das práticas informacionais digitais de mulheres primíparas (BRASILEIRO, 2019). Partindo da análise qualitativa dos discursos de um coletivo 
dessas mulheres (mães pela primeira vez), formado por meio da plataforma digital WhatsApp, e orientado ao enfrentamento de incertezas e desinformações acerca da maternidade em ambientes digitais, o estudo evidenciou a relação envolvendo as emoções, as práticas informacionais e o letramento informacional.

Considerando as práticas dessas mulheres acerca do autogerenciamento da informação (BRASHERS et al, 2002), que evidenciam a dimensão individual da relação com a informação, constatamos que, ao buscar ou explorar ativamente a informação na ambiência digital, as mulheres experimentam emoções diversas (medo, ansiedade, angústia, tristeza) frente às situações de incerteza que se traduzem em dificuldades para a tomada de decisões, como, por exemplo, estabelecer consenso entre as informações disseminadas, traduzir a informação científica, confiar em informações de comentários, assegurar a adequabilidade das informações e encontrar informações relevantes. Outrossim, estas e outras emoções (vergonha, culpa, raiva) são experimentadas nas situações em que as mulheres se conectam com as informações em suas redes sociais de modo não dirigido, quando, por exemplo, inesperadamente, conteúdos delicados são visualizados, informações compartilhadas e atos nas redes ameaçam suas faces, e informações sobre certos temas julgados importantes chegam de forma desencontrada (BRASILEIRO, 2019).

O que chama a atenção é que essas emoções transitórias vinculadas às incertezas informacionais se articulam com o estado emocional prévio a respeito da maternidade. Ou seja, os capitais emocionais incorporados, resultantes das experiências emocionais coletivas e históricas acerca do significado de ser mãe, cristalizadas em símbolos maternos que são recarregados no ambiente, exercem influência sobre as emoções transitórias vinculadas às incertezas do contexto, e, conjuntamente, sobre os modos de julgar, sentir e agir diante das informações. Por outro lado, o estudo destaca que as informações que circulam nas ambiências digitais, cada vez mais complexas e atreladas aos padrões de felicidade impostos pela midiatização (SODRÉ, 2013), quando postas em relação às experiências da transição da maternidade (SILVA, 2012), provocam emoções que tensionam os capitais emocionais incorporados e, logo, os valores de informação a eles vinculados, gerando rupturas nas referências de verdade e inseguranças para seguir em frente.

Esse tensionamento - que é informacional, por se tratar de um questionamento das disposições e/ou valores informacionais habituais, e também emocional, sobretudo se observado in loco frente à desarmonia dos capitais emocionais -, quando deixa de ser situacional e passa a se prolongar no tempo, contribui para a emergência de um estado de incerteza informacional (BRASILEIRO, 2019). Em tempos suscetíveis à desinformação e incertezas, o estado de incerteza informacional seria uma categoria praxiológica que possibilitaria observar empiricamente a realidade (des) informacional enfrentada na experiência dos sujeitos, durante adversidades ou crises, em detrimento de categorias objetivistas que, quando distantes da camada da experiência, podem reduzir os sujeitos a uma posição passiva frente aos desdobramentos da desinformação.

Enquanto o termo "estado" - relacionado ao modo de estar no momento - abarca a vulnerabilidade emocional provisória decorrente da tensão entre os capitais emocionais (vinculados aos valores de informação prévios) e às emoções transitórias que emergem das situações de incerteza sobre as informações, o termo "incerteza informacional” demarca as múltiplas percepções de desinformação (KARLOVA; FISHER, 2013) - inerentes ao ambiente complexo - que dificultam os objetivos informacionais. A categoria estado de incerteza informacional, portanto, sugere que os 
sujeitos sentem e percebem as distorções informacionais, e que sentem e percebem uma necessidade de criar estratégias alternativas para enfrentá-las.

Ademais, embora seja experimentado como vulnerabilidade, o estado de incerteza informacional pode ser entendido como oportunidade de construção de uma nova perspectiva informacional - direcionada ao bem comum - à medida que desloca os sujeitos de suas bases informacionais ancoradas, muitas vezes, em símbolos idealizados por um ambiente desigual e violento, e, ao mesmo tempo, desperta a necessidade de vinculação com os outros - para além de suas redes primárias (laços fortes) - a fim de superar o desconhecido/desconforto. A esse respeito, consideramos que a superação do estado de incerteza informacional e, logo, a ressignificação das disposições informacionais só são possíveis quando os sujeitos conseguem reconstruir seus capitais emocionais em sintonia com novos valores e práticas informacionais. Assim, as emoções adquiridas se configuram como um "fixador" que conecta os sujeitos a uma nova perspectiva.

Nesse sentido, as interações e a vinculação com os outros são fundamentais. Considerando que a resiliência informacional é um processo que se estabelece a partir das relações e redes sociais (LLOYD, 2014; 2015), podemos dizer que ambas são o caminho para a aquisição de capitais emocionais vinculados a uma nova perspectiva informacional. Para tanto, as conexões de laços fracos, imprescindíveis à aquisição de novos recursos informacionais (JOHNSON; CASE, 2012), precisam ser transformadas em conexões de laços fortes, a fim de se tornarem laços/símbolos carregados de sentimento de solidariedade, moralidade e confiança capazes de conectar consciências coletivas e individuais sobre a informação e práticas informacionais recém-construídas. Caso contrário, sem essa coesão emergente, os sujeitos podem retornar às bases informacionais habituais a fim de reduzirem as incertezas e preservarem seus capitais emocionais prévios ou, em outra direção, permanecerem retidos aos laços fracos com prejuízo de esvaziamento emocional e depressão. É possível que os efeitos depressivos e de exaustão emocional peculiares à infodemia da COVID-19 (OPAS, 2020) tenham sido potencializados por essa segunda direção.

Diante do exposto, torna-se relevante compreender as dinâmicas emocionais que envolvem a transformação dos laços fracos em laços fortes - no decorrer das situações de interação sociotécnica em contextos de transição - e, assim, contribuem à consolidação da resiliência informacional. Partindo do princípio de que o processo se inicia com as rupturas/desafios que provocam o estado de incerteza informacional e se articula com as práticas colaborativas constituidoras de sentimentos coletivos, algumas questões de natureza socioemocional podem servir como indicadores analíticos aos estudos sobre o fenômeno da transição informacional:

Quais são as emoções e sentimentos associados aos valores de informação do ambiente habitual? Quais são os fatores de incerteza que tensionam essas emoções e valores? Quais são as emoções e sentimentos transitórios que decorrem das incertezas? Como esse estado emocional dificulta ou impede as práticas informacionais direcionadas à transição? Quais são os fatores emocionais que dificultam ou impedem as práticas informacionais colaborativas? Quais são os fatores emocionais e as condições que contribuem para as práticas informacionais colaborativas? Quais são as emoções e sentimentos coletivos produzidas pela colaboração? Quais são os valores informacionais que se vinculam a essas emoções? Como as emoções vinculadas à novos valores reorientam as novas práticas informacionais dos sujeitos? Quais são os símbolos de associação que cristalizam e/ou materializam as emoções e valores informacionais ao longo do tempo? 
Tais questões são apenas uma referência à pesquisa empírica. Sem dúvidas, podem ser alargadas ou aprofundadas conforme a situação, considerando, empiricamente, as diferentes materialidades - relacionadas ao ecossistema digital - que co-constituem as práticas, a exemplo de dispositivos, plataformas, algoritmos, entre outras (MORGANTHOMAS et al, 2020). Destaca-se, aqui, a perspectiva teórica de Collins (2004) como um recurso teórico-metodológico apropriado para essas questões socioemocionais. Aliada à teoria de Collins, incorporando a materialidade dos dispositivos móveis (telefones), a perspectiva de (LING, 2008) pode ser útil à compreensão do arranjo "Smartphone-WhatsApp" na co-constituição das práticas informacionais colaborativas frente às incertezas associadas às plataformas de mídia social e da web. Ambas as perspectivas serviram de base ao modelo (Figura 1) que delineamos (BRASILEIRO, 2019) acerca do processo socioemocional da resiliência informacional digital. Contudo, ressaltamos que outros arranjos materiais e tecnologias digitais precisam ser considerados em paralelo, uma vez que, também, atuam nas determinações das emoções e sentimentos que envolvem as práticas informacionais.

\section{PRÁtICAS INFORMACIONAIS COLABORATIVAS EM REDES DIGITAIS}

O modelo apresentado (Figura 1) ilustra como pode se desenvolver, numa perspectiva socioemocional, o processo de resiliência informacional em redes digitais. Inicialmente, o modelo aborda as práticas informacionais no ambiente informacional virtual agenciadas no contexto individual - sem uma rede colaborativa previamente instituída (BRASILEIRO, 2019). O modelo evidencia possíveis barreiras à informação que incidem sobre as desinformações e as emoções.

Figura 1: Modelo da resiliência informacional em redes sociais virtuais.

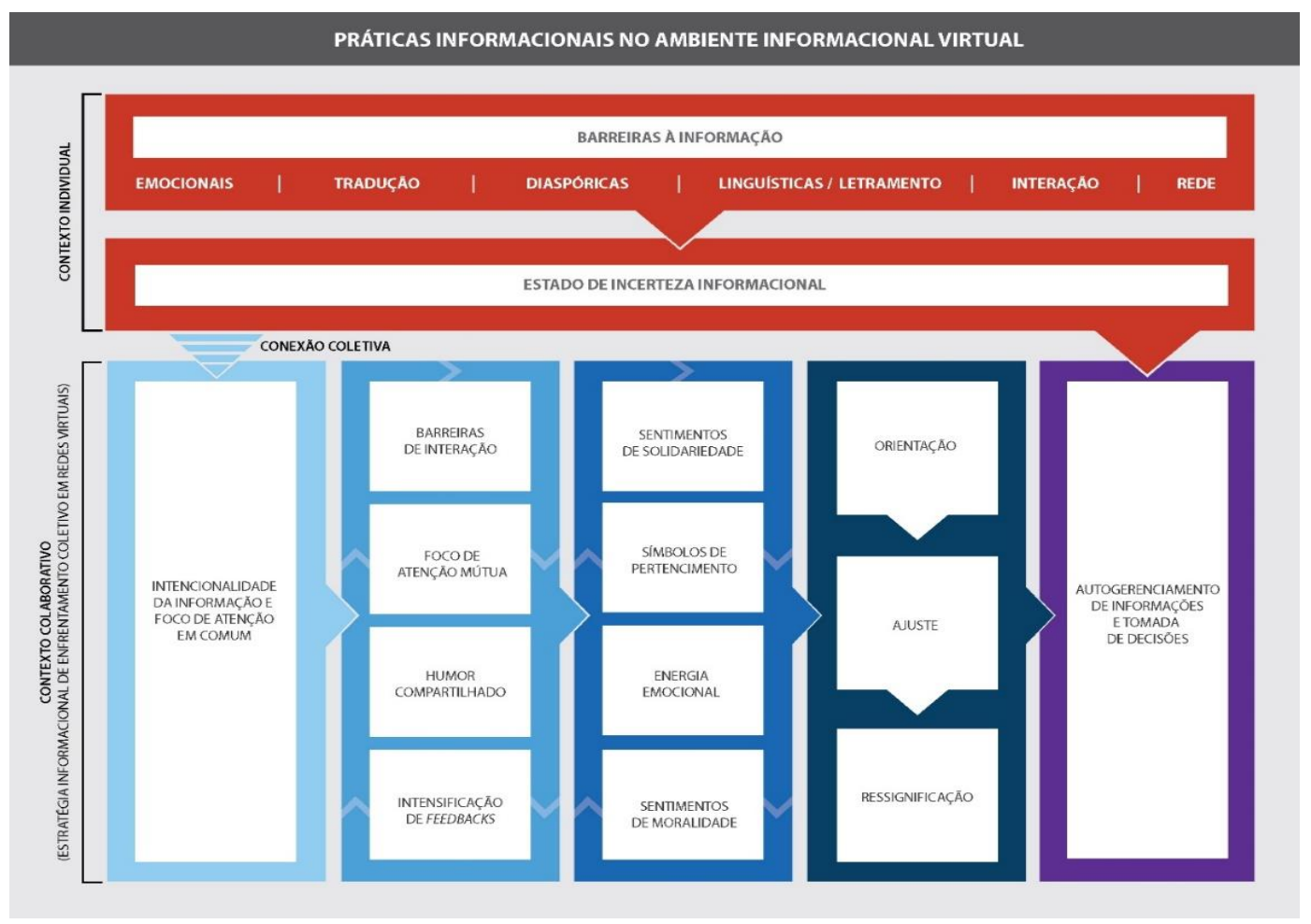

Fonte: Brasileiro (2019), baseado em Collins (2004) e Lloyd (2014) 
As barreiras à informação revelam uma malha de barreiras inter-relacionadas: emocionais (tensões entre capitais emocionais e emoções transitórias); tradução (linguagem da informação científica inadequada); diaspóricas (tensões entre práticas habituais e ambiente informacional); letramento (habilidades e competências limitadas); interação (objetivos sociáveis conflitantes com os informacionais); redes (limitações ou excesso de conexões informacionais). Essas e outras possíveis barreiras podem gerar o estado de incerteza informacional, discutido na seção anterior.

\section{Estado de incerteza informacional: tensões entre emoções e informações}

Trata-se de uma interferência negativa nas capacidades individuais de autogerenciamento de informações e tomada de decisões. Isso inclui uma interferência no estado emocional dos sujeitos frente às demandas informacionais que emergem da experiência. A experimentação situacional desse estado pode deslocar "os sujeitos à conexão coletiva, ao direcionar o estado de consciência para a informação colaborativa" (saberes construídos em colaboração digital), "constituindo a estratégia informacional de enfrentamento coletivo em redes virtuais". Esse agrupamento "se torna possível à medida que existe o reconhecimento de uma intencionalidade da informação em comum", ou seja, de que outros sujeitos também têm a consciência direcionada à informação colaborativa acerca das incertezas do contexto. Isso se torna possível quando os sujeitos percebem, durante a navegação e interação no ecossistema digital, um foco de atenção em comum, que pode acontecer a partir da visualização de informações/emoções publicadas nas mídias sociais, de recomendações ou de intermediações (BRASILEIRO, 2019, p. 134).

\section{Colaboração em redes digitais: transformando emoções e informações em sentimentos}

A colaboração informacional digital "envolve outras barreiras de interação que emergem nos instantes iniciais dos encontros informacionais" e evitam o engajamento com as práticas colaborativas, sugerindo práticas cautelosas. Essas barreiras se manifestam nas conexões de laços fracos e podem envolver duas dimensões ligadas à privacidade e reputação: "1. desconfiança e insegurança para o compartilhamento de informações íntimas e/ou pessoais; e 2. preocupação em evitar impressões indesejadas nos [...] encontros informacionais". A transformação acontece a partir do momento em que os sujeitos se conectam, por meio das expressões/emoções simuladas pelos recursos linguísticos e paralinguísticos digitais, com experiências relevantes e acolhedoras. Logo, constatam que: os outros lidam com incertezas comuns; as informações se ajustam às realidades vivenciadas; os outros buscam saberes coletivos; a rede não se prende a uma verdade absoluta. Passam, assim, a buscar e compartilhar informações pessoais de modo a comunicar a atenção entre si e desenvolver o foco de atenção mútua e o humor compartilhado. Ambos se reforçam mutuamente a partir da intensificação de feedbacks (interações síncronas envolvendo a intermediação de informações e o compartilhamento de experiências), gerando a experiência intensa de emoção compartilhada (flow). Logo, os sujeitos passam a se sentir mais íntimos uns dos outros, mais seguros sobre o propósito da estratégia colaborativa e, principalmente, mais dispostos a ajudar e acolher pessoas que enfrentam incertezas similares. Essa microdinâmica emocional pode gerar a consciência informacional direcionada ao bem comum (BRASILEIRO, 2019, p. 134-135). 


\section{Resiliência informacional em redes digitais: agência dos sentimentos coletivos nas práticas}

A consciência coletiva direcionada ao bem comum, "fundada em uma experiência emocional, se expressa em alguns elementos importantes para a emergência e reprodução da coesão social, a qual condiciona o desenvolvimento de competências" e molda o cenário informacional. Dados por Collins (2004), os elementos são: (a) os sentimentos de solidariedade (determinam o compromisso prolongado com as incertezas dos outros de modo a possibilitar o compartilhamento de experiências e a intermediação de informações); (b) os símbolos de pertencimento (preservam e reproduzem as emoções e os valores de informação que sustentam a solidariedade a ponto de ampliar a rede e servir de referência ao entendimento prático e às informações do ambiente); (c) a energia emocional (os capitais relacionados aos sentimentos de autoconfiança, entusiasmo e iniciativa - motivam a colaboração, asseguram a tomada de decisões e a seleção das fontes, regulam o juízo moral das atividades de compartilhamento e intermediação, fixam os novos significados atribuídos ao valor de informação); (d) os sentimentos de moralidade (sustentam os princípios morais que equilibram as práticas informacionais colaborativas no tempo, como as atividades consideradas aprovadas - e. g. busca de informação para os outros - e as não aprovadas - e. g. publicação de informações restritas) (BRASILEIRO, 2019, p. 136-137).

Tais elementos, nessa perspectiva, podem agenciar os processos de orientação, adaptação e ressignificação dados por Lloyd (2014). A orientação acontece quando os sujeitos passam a se conectar com os fragmentos de informações provenientes das fontes digitais (formais e informais) a partir do agenciamento solidário dos mediadores info-comunicacionais que emergem da rede (envolvendo "links de websites, blogs, páginas de redes sociais, documentos [...] experiências pessoais e posicionamentos médicos"). Essa experiência coletiva, além de introduzir os sujeitos ao novo ambiente, possibilita a validação colaborativa das informações diversas, além da transliteração e adequação da informação às realidades particulares. O ajustamento ocorre quando os sujeitos modificam seus hábitos e atividades a partir das experiências emocionais de encontrabilidade da informação mediadas e cristalizadas pela/na rede. Passam a adotar a rede como método para buscar informações e validá-las a fim de construir conhecimentos práticos - "uma alternativa frente aos motores de busca tradicionais da web, como o Google” (BRASILEIRO, 2019, p. 138). Há, assim, a superação das barreiras e a criação de um lugar de referência.

A ressignificação envolve a reformulação de práticas e a atribuição de novos significados às representações/incertezas do contexto (envolvendo o entendimento sociocultural da informação). A ressignificação pode reconstruir o entendimento sobre a informação, reproduzida de maneira descontextualizada, desordenada ou padronizada pelas fontes digitais (formais e informais) do ambiente informacional. Assim, as incertezas que emergem da infodemia - que podem dificultar os objetivos informacionais - passam a ser experimentadas emocionalmente de forma positiva e significativa (alta EE). Dessa forma, a ressignificação "culmina na sensação [...] de segurança frente aos processos informacionais e, ao mesmo tempo, na sensação de [...] suporte coletivo" e emocional à socialidade. Com efeito, o processo contribui para o autogerenciamento de informações e tomada de decisões, ao permitir uma negociação dos objetivos informacionais e conflitantes ancorada nos sentimentos de associação (BRASILEIRO, 2019, p. 139). Esses sentimentos possibilitam a equação das dinâmicas infodêmicas provenientes dos múltiplos canais e, principalmente, a mediação entre as práticas e os valores do ambiente informacional. 


\section{CONSIDERAÇÕES FINAIS}

Considerando a complexidade das conexões e interações do ambiente digital, em especial as que envolvem a hipercirculação de informações e a superexposição do eu nas redes digitais, a perspectiva socioemocional pode oferecer subsídios analíticos à compreensão do processo colaborativo da resiliência informacional digital à medida que indica: (i) as tensões emocionais experienciadas pelos sujeitos frente à diáspora digital e às práticas informacionais digitais que concorrem com seus múltiplos objetivos; (ii) as conexões digitais com os laços fracos e a transformação desses laços em fortes; (iii) a construção de novas práticas significativas e suas relações com os modos de ação/decisão. Acreditamos que tal perspectiva, articulada à perspectiva relacional de Annemaree Lloyd (que abarca a materialidade da Teoria da Prática e as redes e relações sociais), pode contribuir para investigações futuras sobre os sentimentos coletivos nos processos de constituição e desestabilização de cenários informacionais, como o da COVID-19.

A infodemia gerada pela COVID-19 revelou que os desafios informacionais enfrentados em crises sanitárias globais envolvem a desestabilização dos capitais emocionais que sustentam as práticas informacionais. A reboque, emergem incertezas e emoções transitórias que, potencializadas pelas dinâmicas das plataformas digitais, desconectam as pessoas dos seus cenários. Não foi à toa que, durante a crise, as autoridades de saúde passaram a adotar as plataformas digitais - com o auxílio de celebridades e influenciadores - a fim de mobilizar sentimentos coletivos em sincronia com orientações informacionais (PINTO et al., 2020). Diante disso, considerando o caráter situacional e emergente da resiliência informacional, sugerimos que: os capitais emocionais adquiridos nas experiências informacionais colaborativas agenciadas nas plataformas determinam as atividades (e. g. compartilhamento) e habilidades informacionais relacionadas às crises; e os sentimentos de associação construídos moldam as práticas informacionais ao mesmo tempo em que medeiam a relação com as informações do ambiente.

Nessa perspectiva, tanto as tecnologias digitais quanto os sentimentos de associação emergentes podem ser úteis à compreensão das práticas de letramento informacional construídas pelos sujeitos durante crises ou infodemias. Isso porque podem revelar diferentes formações socioculturais emergentes, inclusive práticas informacionais negacionistas e de propagação do ódio que podem circular nas mídias sociais e agravar os efeitos infodêmicos. Em outras palavras, podem atuar como indicadores às estratégias de reforço, reorientação e/ou desconstrução de práticas emergentes. Nesse sentido, considerando as limitações desse artigo, outras categorias operacionais podem ser sistematizadas em estudos futuros a fim de sustentar análises sobre a relação entre os sentimentos de associação e as práticas informacionais no ecossistema digital.

\section{FINANCIAMENTO}

O presente trabalho foi realizado com apoio da Coordenação de Aperfeiçoamento de Pessoal de Nível Superior - Brasil (Capes) - Código de Financiamento 001.

\section{REFERÊNCIAS}

ARAÚJO, C. A. À. Paradigma social nos estudos de usuários da informação: abordagem interacionista. Informação \& Sociedade, v. 22, n. 1, p. 145-159, 2012. 
ARAÚJO, C. A. À. O que são "práticas informacionais"?. Informação em Pauta, v. 2, n. esp. p. 217-236, 2017.

BOURDIEU, P. The forms of capital. In: RICHARDSON, J. (Ed.). Handbook of theory and research for the sociology of education. New York: Greenwood, 1986.

BRASHERS, D. E.; GOLDSMITH, D. J.; HSIEH, E. Information seeking and avoiding in health contexts. Human Communication Research, v. 28, n. 2, p. 258-271, 2002.

BRASILEIRO, F. S. A resiliência informacional no contexto da microcefalia. Pesquisa Brasileira em Ciência da Informação e Biblioteconomia, v. 12, n. 2, p. 339-347, 2017.

BRASILEIRO, F. S. Resiliência informacional em redes sociais virtuais: práticas colaborativas, emoções e mobilidade. João Pessoa: Editora UFPB, 2019.

COLLINS, R. Interaction ritual chains. New Jersey: Princeton, 2004.

COX, A. M. An exploration of the practice approach and its place in information science. Journal of Information Science, v. 38, n. 2, p. 176-188, 2012.

GOFFMAN, E. Interaction ritual: essays on face-to-face behavior. New York: Doubleday, 1967.

GONZÁLEZ DE GÓMEZ, M. N. Novas fronteiras tecnológicas das ações de informação: questões e abordagens. Ciência da Informação, v. 33, n. 1, p. 55-67, 2004.

HICKS, A.; LLOYD, A. Article It takes a community to build a framework: Information literacy within intercultural settings. Journal of Information Science, v. 42, n. 3, p. 334343, 2016.

JOHNSON, J. DAVID.; CASE, D. O. Health information seeking. New York : Peter Lang, 2012.

KARLOVA, N. A.; FISHER, K. E. A social diffusion model of misinformation and disinformation for understanding human information behaviour. Information Research, v. 18, n. 1, p. 1-17, 2013.

LING, R. S. The mediation of ritual interaction via the mobile telephon. In: Katz, J. (Ed.) Handbook of mobile communication. MIT Press, 2008.

LLOYD, A. Framing information literacy as information practice: site ontology and practice theory. Journal of Documentation, v. 66, n. 2, p. 245-258, 2010.

LLOYD, A. Trapped between a rock and a hard place: what counts as information literacy in the workplace and how is it conceptualized?. Library Trends, v. 60, n. 2, p. 277-296, 2011.

LLOYD, A. Building information resilience: how do resettling refugees connect with health information in regional landscapes: implications for health literacy. Australian Academic and Research Libraries, v. 45, n. 1, p. 48-66, 2014.

LLOYD, A. Stranger in a strange land: enabling information resilience in resettlement landscapes. Journal of Documentation, v. 71, n. 5, p. 1029-1042, 2015. 
MCKENZIE, P. J. A model of information practices: a model of information practices in accounts of everyday-life information seeking. Journal of Documentation, v. 59, n. 1, p.19-40, 2003.

MORGAN-THOMAS, A.; DESSART, L.; VELOUTSOU, C. Digital ecosystem and consumer engagement: a socio-technical perspective. Journal of Business Research, 2020. No prelo.

O'BRIEN, M.; MOORE, K.; MCNICHOLAS, F. Social media spread during Covid-19: the pros and cons of likes and shares. Irish Medical Journal, v. 113, n. 4, p. 52, 2020.

OJEDA, E. N. S. Uma concepção latino-americana: a resiliência comunitária. In: MELILLO, A.; OJEDA, E. N. S. (Ed.). Resiliência: descobrindo as próprias fortalezas. Porto Alegre: Atmed, 2005.

OPAS. Entenda a infodemia e a desinformação na luta contra a COVID-19. Disponível em: www.paho.org/ish. Acesso em: 22 out. 2020.

PINTO, P. A.; BRASILEIRO, F. S.; ANTUNES, M. J. L; ALMEIDA, A. M. P. COVID-19 no Instagram: práticas de comunicação estratégica das autoridades de saúde durante a pandemia. Comunicação Pública, v. 15, n. 29, 2020.

PUTNAM, R. D. Bowling alone the collapse and revival of american community. New York, 2000.

RECUERO, R. Atos de ameaça à face e à conversação em redes sociais na internet. In:

PRIMO, A. (Ed.). Interações em rede. Porto Alegre: Sulina, 2013.

ROCHA, J. A. P.; GANDRA, T. K. Práticas informacionais: elementos constituintes. Informação \& Informação, v. 23, n. 2, p. 566-595, 2018.

SAVOLAINEN, R. Information behavior and information practice: Reviewing the "umbrella concepts" of information-seeking studies. Library Quarterly, v. 77, n. 2, p. 109-132, 2007.

SAVOLAINEN, R. Everyday information practices: a social phenomenological perspective. Lanham, MD: Scarecrow Press, 2008.

SCHATZKI, T. The site of organizations. Organization Studies, v. 26, n. 3, p. 465-484, 2005.

SILVA, S. DE C. M. Reconstruções da maternidade por mães na transição dos filhos para a vida adulta. 2012. Dissertação (Mestrado em Psicologia) - Programa de PósGraduação em Psicologia, Universidade Federal da Bahia, Salvador, 2012.

SODRÉ, M. Antropológica do espelho: uma teoria da comunicação linear e em rede. 8. ed. Petrópolis: Vozes, 2013.

ZAROCOSTAS, J. How to fight an infodemic. The Lancet, v. 395, n. 10225, p. 676, 2020. 